\title{
Quality of life after epilepsy surgery
}

\author{
M W Kellett, D F Smith, G A Baker, D W Chadwick
}

\begin{abstract}
Objective-To assess the relation between seizure status and quality of life after surgery for drug resistant epilepsy, using a previously validated quality of life model developed for use in epilepsy.

Methods-A retrospective postal survey was made on 94 patients who underwent surgery for epilepsy between 1986 and 1994, and 36 patients who after investigation during the same period were found to be unsuitable for surgery. A health related quality of life model was used containing validated measures of anxiety, depression, self esteem, mastery, impact of epilepsy, affect balance, stigma, overall health status, and overall quality of life, to examine the relation between postoperative seizure status and quality of life.

Results-Overall $47.9 \%$ of patients were seizure free after surgery. On all measures seizure free patients scored significantly better than either patients deemed unsuitable for surgery or those having more than 10 seizures per year after surgery. Patients having less than 10 seizures per year obtained intermediate scores. There was no difference between the groups unsuitable for surgery or having more than 10 seizures per year postoperatively. Employment rates were significantly different between groups, $80 \%$ of seizure free and $53 \%$ of patients having less than 10 seizures per year in gainful employment postoperatively, compared with $28 \%$ and $27 \%$ of patients having greater than 10 seizures per year or those who were unsuitable for surgery.

Conclusions-Within broad categories, postoperative quality of life is clearly related to seizure outcome, but the study emphasises the importance of long term follow up in defining the tangible psychosocial effects of freedom from seizures.
\end{abstract}

The Walton Centre for Neurology and Neurosurgery, Rice Lane, Liverpool L9 1AE

$\mathrm{M}$ W Kellett

D F Smith

G A Baker

D W Chadwick

Correspondence to: Dr M W Kellett, The Walton Centre for Neurology and Neurosurgery, Rice Lane, Liverpool L9 1AE.

Received 11 July 1996 and in revised form 24 February 1997

Accepted 10 March 1997

Keywords: epilepsy surgery; quality of life

Chronic drug resistant epilepsy is a disabling condition that impairs quality of life. ${ }^{1}$ It is associated with an increased incidence of psychiatric and psychological morbidity ${ }^{2}$ especially anxiety and depression. ${ }^{3}$ Its sufferers are stigmatised, ${ }^{4}$ have low self esteem, ${ }^{5}$ are socially disadvantaged, and are less likely to be employed. ${ }^{16}$

For patients with drug resistant epilepsy, surgery may abolish seizures in up to two thirds of cases shown to be suitable for surgery, ${ }^{78}$ but it is a destructive procedure, carrying small risks of death or permanent neurological deficit: hemiparesis, hemianopia, dysphasia, or memory problems. Freedom from seizures is presumed to improve quality of life, but some patients have difficulty adapting to freedom from seizures, ${ }^{9}$ whereas others experience surgical complications which may be as disabling as chronic epilepsy. Therefore, there is a need for more sensitive measures of postoperative outcome, including psychosocial functioning and quality of life. ${ }^{10}$

Health related quality of life reflects the impact of a disease and its treatment on a person's physical, social, and psychological wellbeing. The impact of chronic illness on health related quality of life varies between conditions and, therefore, disease specific measures are likely to be more sensitive to these effects than generic measures. ${ }^{11}$ Some studies report that good psychosocial outcome is dependent on being completely seizure free postoperatively, ${ }^{12-14}$ suggesting that patients with postoperative seizures, even at reduced frequency, may have a worse outcome compared with their preoperative baseline status. ${ }^{15}$ These studies used generic measures or measures which may not be sensitive to the changes experienced by surgically treated patients. More recent studies using validated quality of life measures specifically developed for use in epilepsy (epilepsy surgery inventory 55 (ESI 55)) have found that quality of life significantly improves for seizure free patients but also to a lesser extent in patients having auras only, compared with those with ongoing seizures postoperatively. ${ }^{16-18}$ Recently, Vickrey et al reported significant improvements on five of 11 scales of the ESI 55 but no improvement on the other six, in surgically treated compared with medically treated patients evaluated between 1974 and $1990 .^{19}$

During the past five years, we have developed and refined a health related quality of life model for patients with epilepsy. ${ }^{20}$ We used this model to compare quality of life outcomes of patients undergoing surgery with those who, after investigation, were found to be unsuitable for surgery.

\section{Methods}

A self administered postal questionnaire was sent to 118 patients who underwent epilepsy surgery at the Walton Centre For Neurology and Neurosurgery between 1986 and June 1994 , and to 70 patients who, after investigation during the same period, were found to be unsuitable for surgery. The questionnaire collected demographic data, information on seizure type and frequency, and employed precoded and open questions. This health related 


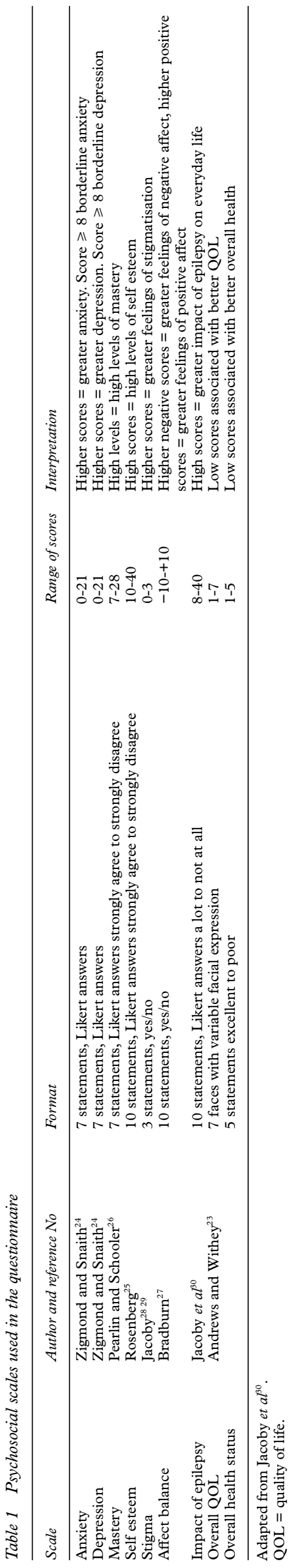

quality of life model (table 1) contained measures of anxiety and depression, self esteem, mastery, affect balance, stigma, impact of epilepsy, overall quality of life, and health status. These scales have been found to be reliable and valid in patients with both refractory epilepsy ${ }^{29}$ and epilepsy in remission. ${ }^{30}{ }^{31}$

For purposes of analysis patients were placed in four categories; seizure free postoperatively (SF), less than 10 seizures per year postoperatively $(S<10)$, more than 10 seizures per year postoperatively $(S>10)$, unsuitable for surgery and managed medically (NSurg). We chose these seizure frequencies as similar definitions have been used previously in studies reporting the results of epilepsy surgery. ${ }^{8}{ }^{18}$ To be classified as seizure free, patients had to have been seizure free for at least the year immediately before the censor date. Before the study we had planned to subdivide patients with postoperative seizures into those with auras only and those with attacks similar to the preoperative type, on the basis that auras may have less impact on quality of life. ${ }^{18}$ However, the numbers of patients reporting postoperative auras only was too small for suitable statistical analysis, and, therefore, auras were treated as seizures and classified accordingly. This may have artificially reduced the psychological scale scores for patients having frequent seizures postoperatively.

\section{STATISTICS}

As the numbers in the groups are small, median scores and quartile ranges are quoted unless otherwise stated. The data were analysed using Arcus Pro computer software. Tests of significance used were the Mann-Whitney $U$ test with exact probabilities corrected for ties, Kendall's $\tau$ b correlation coefficient corrected for ties and continuity corrected, and the Kruskal-Wallis one way analysis of variance (ANOVA) with multiple comparisons if significant differences were detected. ${ }^{32}$ For categorical variables odds ratios (ORs) with exact 95\% confidence intervals ( $95 \%$ CIs) relative to the NSurg group were calculated, ${ }^{33}$ unless otherwise stated. Information was missing on some of the scales; this is indicated by ${ }^{\star}$ in the text.

\section{Results}

SEIZURE OUTCOME

Ninety four of $118(80 \%)$ patients undergoing surgery and 36 of $70(51 \%)$ patients unsuitable for surgery returned questionnaires that were suitable for analysis. Nine questionnaires were unsuitable for analysis; seven because of incomplete data and two which were completed by carers and, therefore, contained subjective information only.

Overall, $45(47.9 \%)$ patients were seizure free postoperatively. Twenty of $45(44.4 \%)$ patients having anterior temporal lobectomies, 13 of $24(54.2 \%)$ having amygdalohippocampectomies, 11 of $17(64.7 \%)$ having temporal lesionectomies, and one of eight $(12.5 \%)$ having extratemporal surgery were seizure free (table 2). 


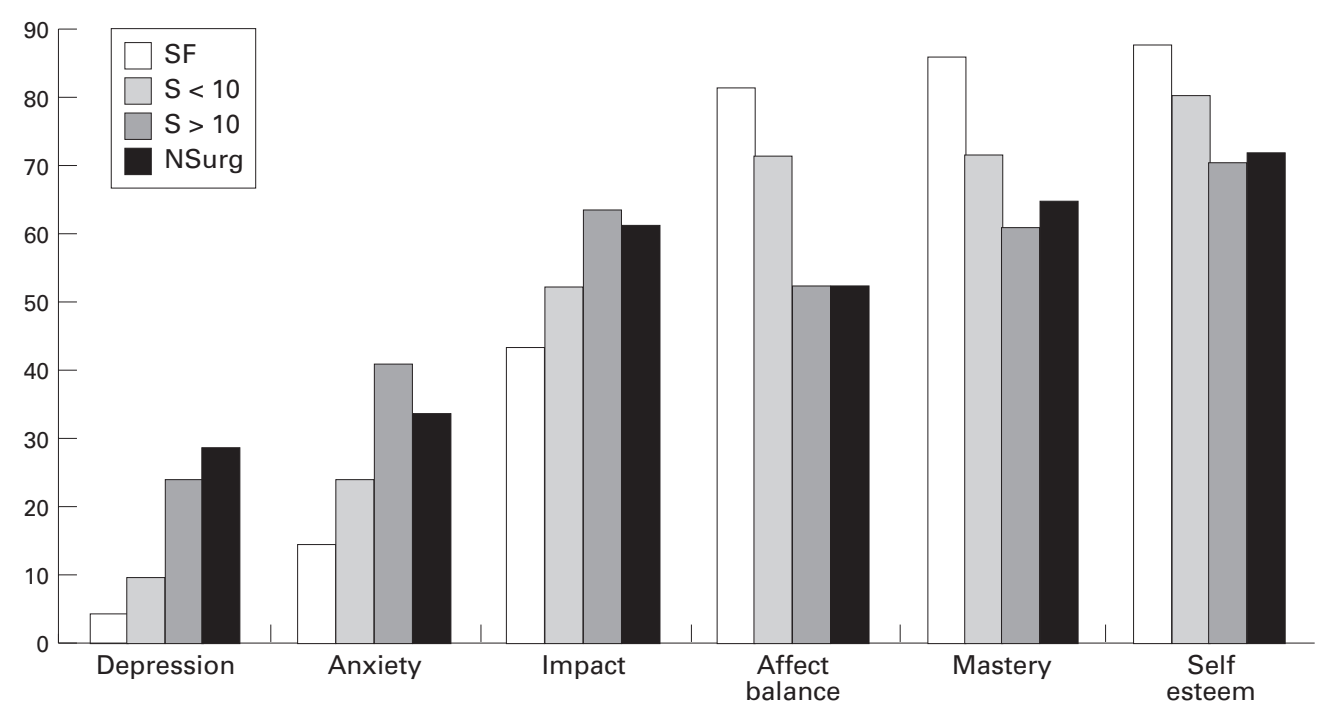

Figure 1 Median depression, anxiety, impact of epilepsy, affect balance, mastery, and self esteem scores linearly transformed to a scale with maximum $=100(S F=$ seizure free; $S<10=$ less than 10 seizures per year; $S>10=$ more than 10 seizures per year; NSurg = no surgery).

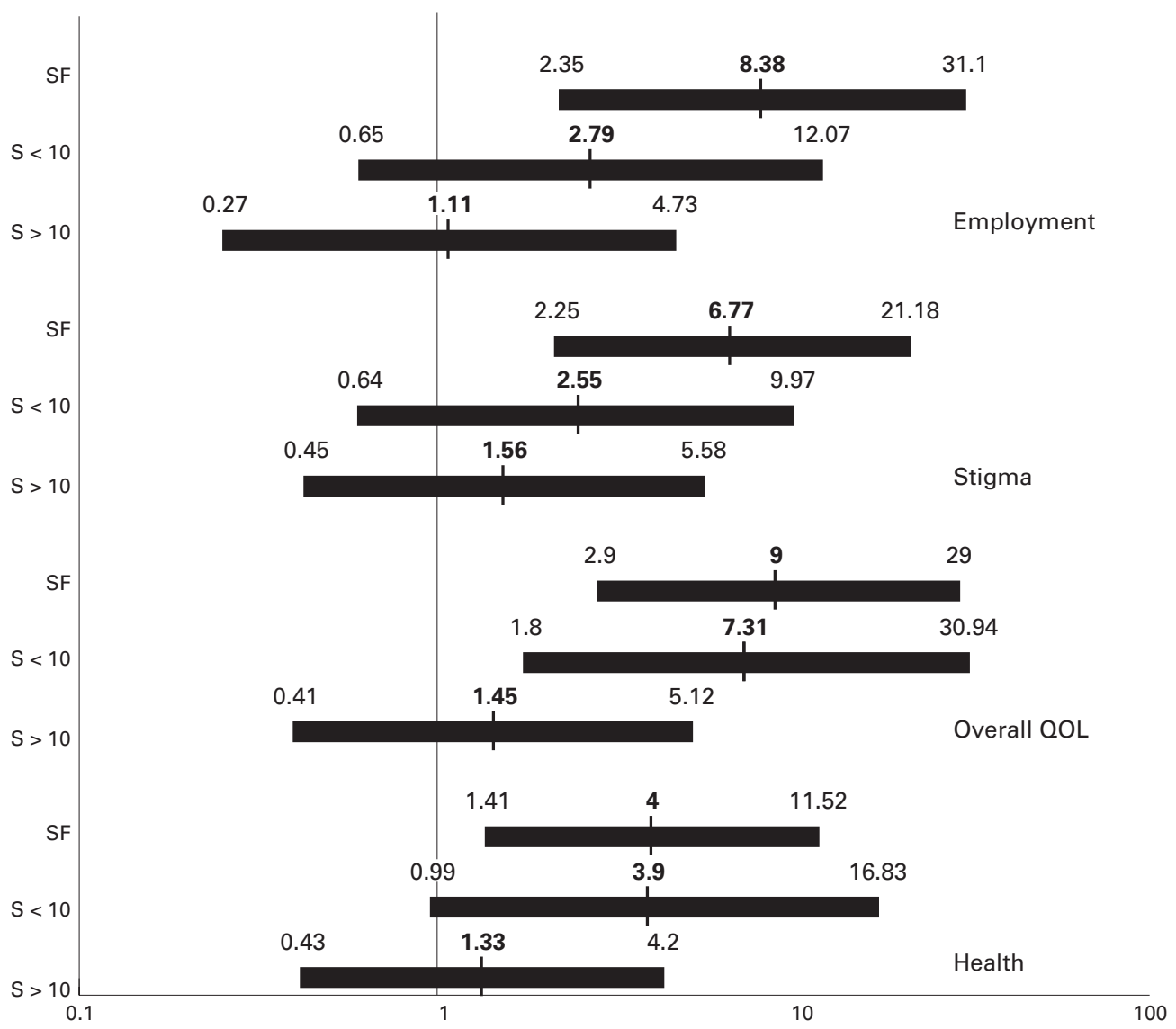

Figure 2 Odds ratios with upper and lower 95\% confidence intervals (calculated relative to NSurg group who by definition have odds ratio $=1$, indicated by the vertical line). (1) Odds of entering employment after surgery. (2) Odds of zero stigma score. (3) Odds of best two of seven overall quality of life scores. (4) Odds of best two of five general health scores.

QUALITY OF LIFE OUTCOME

Patients in the seizure free group had significantly better scores than those having greater than 10 seizures per year or those who were deemed unsuitable for surgery. There were no differences between the $S>10$ and NSurg groups. On all measures the scores of patients with less than 10 seizures per year were between the SF and NSurg or S>10 groups (figs 1 and 2).

On the anxiety scale scores differed significantly between all groups (table 3 and fig 1). On the depression scale scores for both the SF and $S<10$ groups were better than the $S>10$ or NSurg groups (table 3 and fig 1). Mastery scores were significantly better in SF than in 
any of the other groups (table 3 and fig 1). The SF patients were least stigmatised with only $35.6 \%$ of patients reporting positive stigma scores, compared with $57.9 \%, 67.9 \%$ and $77.8 \%$ in the $S<10, S>10^{\star}$, and NSurg patients respectively (fig 2). Self esteem was significantly higher in the SF than S>10 or NSurg with the $S<10$ achieving intermediate scores (table 3 and fig 1). Epilepsy had least impact on the SF group and feelings of wellbeing (affect balance) were greatest in $\mathrm{SF}$ and $\mathrm{S}<10$ groups (table 3 and figs 1 and 2). Similarly self reported general health and overall quality of life were best in the SF group and worst in the $S>10$ and NSurg groups.

EMPLOYMENT AND DRIVING

Eleven of 44 seizure free patients reported being in paid employment before surgery compared with only six of 79 in the other three groups combined (OR 5.82, 95\% CI 21.0 1.75) (table 4). The proportions of patients unemployed before surgery who entered employment after surgery or investigation for surgery were $24 / 33(73 \%) \mathrm{SF}$ and $8 / 17(47 \%)$ $S<10$ compared with $6 / 27$ (22\%) $S>10$ and $7 / 29$ (24\%) NSurg. There was no difference in preoperative educational attainment - that is, proportion of patients obtaining no qualifications, CSE or "O" level equivalents or " $A$ " levels or degrees between the outcome groups $\left(\chi^{2}\right.$ $6 \mathrm{df}=8.33, \mathrm{P}=0.22)$. Similarly, there was no difference in qualifications obtained between employed or unemployed patients in the group as a whole $\left(\chi^{2} 2 \mathrm{df}=0.32, \mathrm{P}=0.85\right)$. Twenty of $45(46 \%)$ seizure free patients obtained driving licences after surgery.

OUTCOME AND POSTOPERATIVE DURATION

There was a weak but significant correlation indicating falling impact of epilepsy scores with increasing postoperative duration $(\tau \mathrm{b}=-0.23$, $\mathrm{Z}=1.996, \mathrm{P}=0.046$ ). On the remainder of the quality of life scales there was no relation between outcome and postoperative duration (table 5). However, there was a tendency for postoperative duration to be longer in seizure free patients who were in gainful employment (median duration $=$ three years) compared with those unemployed (median duration $=2.5$ years; Mann-Whitney $U=83.5, \mathrm{P}=0.07$ ). Similarly, the median postoperative duration was one year longer in those driving (median = three years) compared with those not driving (median $=$ two years; Mann-Whitney $U=$ $333.5, \mathrm{p}=0.011)$.

\section{Discussion}

In this study we administered a health related quality of life model to patients undergoing surgery for epilepsy and compared the results with those for patients found to be unsuitable for surgery. It is a retrospective, cross sectional study and some of the analysis groups have small numbers; therefore, the results should be interpreted with some caution. However, similar methodology has been used in other published studies of postoperative quality of life. ${ }^{19}$

The groups were similar in seizure characteristics; all patients had complex partial or secondarily generalised tonic-clonic seizures, but, because of the small numbers, assessment of outcome was limited to total seizure frequency only. The control group (NSurg) had seizures similar in frequency and nature to those undergoing surgery.

In this postal questionnaire $47.9 \%$ of our respondents were completely seizure free in the year before censor date, and a further three patients had experienced at least two years of freedom from seizures after surgery but then relapsed. One patient in the $S<10$ group and four in the $S>10$ group had auras only, $53.2 \%$ would fall into class I of Engel's classification, ${ }^{7}$ whereas a further $20 \%$ with less than 10 seizures per year would probably fall into class II. Therefore, overall our figures are representative of other studies. ${ }^{7819}$

The study disclosed that quality of life in various psychosocial domains is significantly better in seizure free patients than those who continue to have frequent seizures after surgery for epilepsy or who are unsuitable for surgery. Quality of life in patients with reduced numbers of seizures seems improved but to a lesser degree. These results are at odds with previous studies, which have suggested that

Table 2 Patient characteristics and types of operation performed

\begin{tabular}{|c|c|c|c|c|}
\hline & $\begin{array}{l}\text { Seizure free } \\
(n=45)\end{array}$ & $\begin{array}{l}\text { Less than } 10 \text { seizures per } \\
\text { year }(n=19)\end{array}$ & $\begin{array}{l}\text { More than } 10 \text { seizures per } \\
\text { year }(n=30)\end{array}$ & $\begin{array}{l}\text { No surgery } \\
(n=36)\end{array}$ \\
\hline Mean age (SD) (y) & $33.5(9.2)$ & $30.1 \quad(7.2)$ & $34.5(8.2)$ & $33.6(9.0)$ \\
\hline Age of onset (SD) (y) & $12.4(10.0)$ & $8.17(6.8)$ & $12.2(9.5)$ & $12.4(9.5)$ \\
\hline \multicolumn{5}{|l|}{ Marital status: } \\
\hline Single & 23 & 13 & 13 & 17 \\
\hline Married & 19 & 6 & 14 & 15 \\
\hline Divorced & 3 & 0 & 3 & 4 \\
\hline \multicolumn{5}{|l|}{ Highest qualification: } \\
\hline No formal qualification & 18 & 10 & 13 & 10 \\
\hline CSE, O level, or equivalent & 16 & 5 & 12 & 11 \\
\hline A level, HND, or degree & 11 & 2 & 3 & 12 \\
\hline Other unspecified & 0 & 2 & 2 & 3 \\
\hline \multicolumn{5}{|l|}{ Types of operation: } \\
\hline ATL & 20 & 12 & 13 & \\
\hline AHX & 13 & 4 & 7 & \\
\hline TLEX & 11 & 2 & 4 & \\
\hline ETLEX & 0 & 0 & 5 & \\
\hline Other & $1^{\star}$ & $1 \dagger$ & $1^{\star}$ & \\
\hline
\end{tabular}

$\mathrm{ATL}=$ anterior temporal lobectomy; $\mathrm{AHX}=$ amygdalohippocampectomy; TLEX $=$ temporal lesionectomy $; \mathrm{ETLEX}=$ extra temporal lesionectomy.

* Hemisperectomy; † multiple lobar resection. 


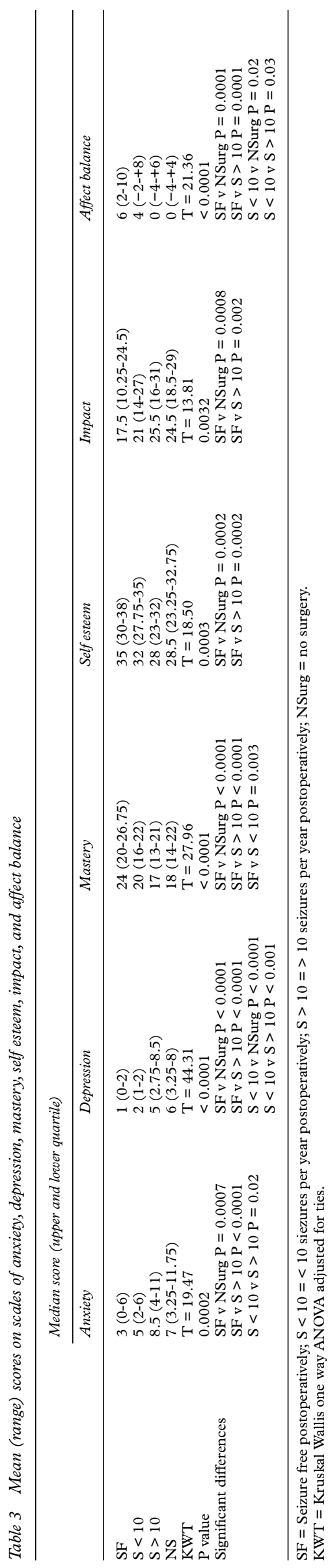

Table 4 Numbers of patients in paid employment before and after surgery or investigation

\begin{tabular}{lcccc}
\hline & $S F$ & $S<10$ & $S>10$ & NSurg \\
\hline Employed before surgery & 11 & 2 & 3 & 1 \\
Entered employment after & & & & 7 \\
surgery & 24 & 8 & 6 & 72 \\
Unemployed after surgery & 9 & 9 & 21 & 22 \\
Total & $44^{\star}$ & 19 & 30 & $30 \dagger$ \\
\hline
\end{tabular}

$\overline{\mathrm{SF}}=$ seizure free postoperatively; $\mathrm{S}<10=<10$ seizures per year postoperatively; $\mathrm{S}>10=>10$ seizures per year postoperatively; NSurg = no surgery.

$\star$ Missing information on one patient.

$\dagger$ Missing information on six patients.

improved psychosocial status after surgery is dependent on being completely seizure free. ${ }^{12} 13$ Rausch and Crandall, using measures including degree of dependency, work performance and family and non-family relationships, found that improvements were dependent on freedom from seizures one year after surgery. ${ }^{12}$ Hermann et al combined generic measures with the Washington psychosocial seizure inventory (WPSI) to obtain an overall psychosocial outcome and again found improvements in the seizure free group only, six to eight months after surgery. ${ }^{13}$ Using the WPSI alone, Seidman-Ripley also found improvements in seizure free patients postoperatively, but noted a possible deterioration in patients who continued to have seizures with reduced frequency compared with their preoperative baseline status. ${ }^{15}$ Two of the above studies used the WPSI, a psychosocial measure designed for epilepsy, which has been criticised because it refers to fixed events in the past which will not change with any outcome, and also because its format utilises yes or no answers which may not be sensitive to change. ${ }^{15}$ The use of generic measures, the short duration of follow up, and generally small numbers, may explain the inability to detect differences in patients with reduced frequency of seizures in the above studies.

We attempted to compare outcome using a control population of medically treated patients. Only two other studies have used this format, and only one study used a validated health related quality of life measure. Guldvog and Loyning, in a large study, found no improvement after surgery using measures of educational status, social status, marital status, need for aid in daily activities, or need to be looked after ${ }^{34}$; measures which may be dependent on postoperative duration and which neglect the wider areas of quality of life. Recently, the results from 248 patients who underwent evaluation for surgery at University of California, Los Angeles between 1974 and 1990, have been reported using the ESI $55 .^{19}$ Overall, scores on five of 11 scales of the ESI 55 (seizure targeted health perceptions, social function, pain, role limitations caused by physical problems, and role limitations caused by emotional problems) significantly improved, with no difference on the other six scales (emotional wellbeing, cognitive function, role limitations caused by memory problems, overall quality of life, physical function, and energy) in the surgery group compared with the non-surgery group. ${ }^{19}$ The 
ESI 55 has already been found capable of distinguishing between different outcome groups based on seizure frequency. ${ }^{17}{ }^{18}$ The failure to detect a greater difference compared with medically treated controls in the latest study probably reflects combining the various outcome groups to give an overall surgery group figure.

We were unable to analyse our patients with auras only because the numbers were too small. In a previous study using the ESI, 55 patients with auras only were found to perform similarly to patients with less than 10 seizures per year after surgery, with scores intermediate between seizure free patients and those having more than 10 seizures per year. ${ }^{18}$ At least four patients in our $S>10$ group had auras only; including them in this group may have impaired our ability to distinguish between the $S<10$ and $S>10$ groups and, therefore, underestimated the differences in quality of life outcome.

All the scales we used detected differences between the groups but the patterns of improvement were not the same on all the scales. The mastery scale disclosed small but significant differences between the seizure free and all other groups. This differs from a previous study suggesting that mastery does not change after surgery even in seizure free patients. ${ }^{35}$ In that study, assessment was performed only six months postoperatively, and, therefore, the patients could be still expected to be coming to terms with freedom from seizures. The mastery scale we used considers wider issues and is likely to be more sensitive. The same mastery scale, used in a placebo controlled trial, ${ }^{29}$ detected a significant difference in favour of patients receiving a novel antiepileptic drug. Furthermore, on intuitive grounds, patients gaining relief from unpredictable adverse events - that is, seizures-would be expected to feel a greater degree of control. Similarly it is not surprising that levels of stigma are lower in the seizure free group than in the other three groups. Perceived stigma $^{36}$ may not resolve until epilepsy is completely cured, thence removing the label of "epileptic."

Psychiatric and psychological morbidity is an important problem in epilepsy, ${ }^{12}$ with clinically significant anxiety and depression being common. ${ }^{37}$ Previous postoperative studies have reported improved depression and reduction in psychological distress but only in patients who were seizure free, those with $75 \%$ or less reduction in seizures showed no

Table 5 Correlation between outcome score and postoperative duration in seizure free patients

\begin{tabular}{llll}
\hline Quality of life scale & Kendall's $T^{u u} b$ & Normalised ratio & Two tailed P value \\
\hline Anxiety & -0.04 & 0.336 & 0.74 \\
Depression & 0.009 & 0.065 & 0.95 \\
Impact & -0.23 & 1.996 & 0.046 \\
Self esteem & -0.056 & 0.499 & 0.618 \\
Affect balance & -0.04 & 0.336 & 0.737 \\
Mastery & -0.075 & 0.651 & 0.515 \\
Overall QOL & -0.016 & 0.12 & 0.905 \\
Overall health & -0.008 & 0.054 & 0.957 \\
\hline
\end{tabular}

Kendall's $\mathrm{T}^{\mathrm{au}} \mathrm{b}$ adjusted for ties and continuity corrected with two tailed $\mathrm{P}$ values. $\mathrm{QOL}=$ quality of life. improvement. ${ }^{13}{ }^{35}$ By contrast, this study identified improvements in psychological wellbeing, notably anxiety and depression, in both the seizure free and $S<10$ groups.

Unemployment is a major problem in people with chronic epilepsy ${ }^{6}{ }^{38}$ especially in areas where competition for jobs is fierce. ${ }^{39}$ Gainful employment is a good predictor of overall wellbeing ${ }^{6}$ and patient satisfaction postoperatively, ${ }^{40}$ and, therefore, represents an important outcome for patients. Furthermore, in defining the proportion of patients likely to become productive members of society, it should be considered as an important measure of the cost effectiveness of epilepsy surgery programmes. Some studies have reported that, although "vocational adjustment" 15 and working capacity $^{34}$ may improve, rates of new employment do not. ${ }^{1941}$ One of the most interesting findings in this study was the difference in employment rates in each group. Seizure free patients were more likely to have been employed before surgery than in the other outcome groups, suggesting that they may be less disabled by their seizures and, therefore, would be more likely to have better postsurgery outcome. However, significantly more previously unemployed people obtained employment in the seizure free group compared with the other groups after surgery, consistent with findings from a recent American study. ${ }^{42}$ The overall employment figure of $80 \%$ in the seizure free group is comparable with recently reported employment rates of $79 \%$ for men and $64 \%$ for women in people with well controlled epilepsy and similar to rates found in the general population. ${ }^{43}$ The finding of better preoperative employment rates in patients who become seizure free implies that other factors influence employability. Clearly baseline preoperative status should be measured in future studies to further elucidate the relation between seizures and health related quality of life.

Outcomes such as driving are potentially important outcome measures, as driving and transport are often cited as major problems, ${ }^{44}$ which are likely to influence many other aspects of quality of life in people with epilepsy. There is a lag phase of at least 18 months between becoming seizure free and obtaining a driving licence in the United Kingdom. The finding of significantly longer outcome duration in seizure free patients who were driving compared with those who were not, suggests that the figure of $45 \%$ obtaining driving licences may increase with further follow up.

There is a lag between improvement in seizure control and reduced levels of anxiety and depression in medically treated patients attending a specialist clinic. ${ }^{45}$ Somewhat surprisingly we failed to show a direct relation between duration of postoperative seizure freedom and any of the psychological measures other than impact of epilepsy. However, the driving and employment data from this and other studies ${ }^{46}$ suggest a lag between freedom from seizures and the tangible psychosocial benefits thereof. Furthermore, the nature of this study (retrospective cross sectional) and 
the few seizure free patients makes it difficult to make categorical statements about the importance of duration of postoperative freedom from seizures but demands that long term psychosocial follow up should be the focus of future prospective studies.

In conclusion, this small retrospective study has shown that health related quality of life is related to postoperative seizure status. However, prospective studies are required to elucidate the role of other factors such as preoperative status and changes in psychosocial status with postoperative duration. Satisfactory studies should be prospective and longitudinal, comparing patients' preoperative and postoperative seizures and psychological status. To produce meaningful statistical data multicentre collaboration will be essential.

We thank Mr J B Miles, Mr P L May, and Mr P R Eldridge, neurosurgeons at the Walton Centre for Neurology and Neurosurgery, without whose industry our research would not have been possible.

1 Levin R, Banks S, Berg B. Psychosocial dimensions of epilepsy: a review of the literature. Epilepsia 1982;23:67181.

2 Dodrill CB, Batzel LW, Queisser HR, Temkin NR. An objective method for the assessment of psychological and social problems among epileptics. Epilepsia 1980;21:12335.

3 Robertson MM, Trimble MR. Depressive illness in patients with epilepsy: a review. Epilepsia 1983;24(suppl 2):S10916

4 Dell JL. Social dimensions of epilepsy: stigma and response. In: Whitman S, Hermann BP, eds. Psychopathology in epilepsy: social dimensions. New York: Oxford University epilepsy: social

5 Ozura J. Psychosocial aspects of epilepsy. Fournal of Neurosurgical Nursing 1979;11:242-6.

6 Collings JA. Psychosocial well being and epilepsy: an empirical study. Epilepsia 1990;31:418-26.

7 Engel J. Outcome with respect to epileptic seizures. In Engel J, ed. Surgical treatment of the epilepsies. New York: Raven press, 1987:553-72.

8 Walczak TS, Radtke RA, McNamara JO, Lewis DV, Luther JS, Thompson E, et al. Anterior temporal lobectomy for complex partial seizures: evaluation, results, and long term follow up in 100 cases. Neurology 1990;40:413-8.

9 Ferguson SM, Rayport M. The adjustment to living without epilepsy. F Nerv Ment Dis 1965;140:26-37.

10 National Institute of Health. Surgery for epilepsy. $7 A M A$ 1990;264:729-33.

11 Guyatt GH, Veldhuyzen Van Zanten SJO, Feeney DH, Patrick DL. Measuring quality of life in clinical trial: a taxonomy and review. Can Med Assoc f 1989;140:1441-8.

12 Rausch R, Crandall PH. Psychological status related to surgical control of temporal lobe seizures. Epilepsia 1982;23: gical control

13 Hermann BP, Wyler AR, Somes G. Preoperative psychological adjustment and surgical outcome are determinants of $\mathrm{cal}$ adjustment and surgical outcome are determinants of
psychological status after anterior temporal lobectomy. $\mathcal{f}$ psychological status after anterior temporal
Neurol Neurosurg Psychiatry 1992;55:491-6.

14 Taylor DC, Falcolner MA. Clinical, socio-economic, and psychological changes after temporal lobectomy for epilepsy. Br F Psychiatry 1968;114:1247-61.

15 Seidman-Ripley JG, Bound VK, Andermann F, Olivier A Gloor P, Feindel WH. Psychosocial consequences of postoperative seizure relief. Epilepsia 1993;34:248-54.

16 Vickrey BG, Hays RD, Graber J, Rausch R, Engel J, Brook $\mathrm{RH}$. A health related quality of life instrument for patients evaluated for epilepsy surgery. Med Care 1992;30:299-319.

17 Vickrey BG, Hays RD, Rausch R, Sutherling WW, Engel JE, Brook RH. Quality of life of epilepsy surgery patients as compared with outpatients with hypertension, diabetes,
heart disease, or depressive symptoms. Epilepsia 1994;35: heart disease.607.

18 Vickrey BG, Hays RD, Engel JE, Spritzer K, Rodgers WH, Rausch R, et al. Outcome assessment for epilepsy surgery: the impact of measuring health related quality of life. Ann Neurol 1995;37:158-66.

19 Vickrey BG, Hays RD, Rausch R, Engel J, Visscher BR, Ary $\mathrm{CM}$, et al. Outcomes in 248 patients who had diagnostic evaluations for epilepsy surgery. Lancet 1995;346:1445-9.

20 Baker GA, Jacoby A, Smith DF, Dewey M, Johnson AL, Chadwick DW. Quality of life in epilepsy: the Liverpool initiative.In: Trimble MR, Dobson WE, eds. Epilepsy and quality of life. New York: Raven Press, 1994:135-50.

21 Zigmond AS, Snaith RP. The hospital anxiety and depression scale. Acta Psychiatr Scand 1983;67:361-70.

22 Pearlin L, Schooler C. The structure of coping. 7 Health Soc Behav 1978;19:2-21.

23 Rosenberg M. Society and adolescent self image. Princeton: Princeton University Press, 1965.

24 Hyman MD. The stigma of stroke. Geriatrics 1971;5:13241

25 Jacoby A. Felt versus enacted stigma: a concept revisited. Evidence from a study of people with epilepsy in remission. Soc Sci Med 1994;38:269-74.

26 Bradburn NM. The structure of psychological well being. Chicago: Aldine, 1969

27 Jacoby A, Baker GA, Smith DF, Dewey M, Chadwick DW. Measuring the impact of epilepsy: the development of a novel scale. Epilepsy Res 1993;16:83-8.

28 Andrews FM, Withey SB. Social indicators of well being. Americans perceptions of life quality. New York: Plenum Press, 1976.

29 Smith DF, Baker GA, Dewey M, Jacoby A, Chadwick DW. Seizure frequency, patient perceived seizure severity, and Seizure frequency, patient perceived seizure severity, and
the psychological consequences of intractable epilepsy. Epilepsy Res 1991;9:231-41.

30 Jacoby A. Epilepsy and the quality of everyday life: findings from a study of people with well-controlled epilepsy. Soc Sci

31 Baker GA, Jacoby A, Smith DF, Dewey ME, Chadwick DW. Development of a novel scale to assess life fulfilment as part of the further refinement of a quality of life model for epilepsy. Epilepsia 1994;35:591-6.

32 Conover WJ. Practical non-parametric statistics. New York: Wiley, 1980

33 Thomas DG. Exact confidence limits for the odds ratio in a two by two table. Applied Statistics 1971;20.

34 Guldvog B, Loyning Y, Hauglie-Hanssen E, Flood S, Byornaes $H$. Surgical versus medical treatment for epilepsy: II. Outcome related to social areas. Epilepsia 1991;32:477-86.

35 Hermann BP, Wyler AR. Depression, locus of control, and the effects of epilepsy surgery. Epilepsia 1989;30:332-8.

the effects of epilepsy surgery. Epilepsia 1989;30:3

37 Robertson MM, Trimble MR, Townsend HRA. PhenomRobertson MM, Trimble MR, Townsend HRA. Phenom-
enology of depression in epilepsy. Epilepsia 1987;28:36472 .

38 Scambler G, Hopkins A. Social class, epileptic activity and disadvantage at work. $\mathcal{F}$ Epidemiol Community Health 1980; 34:129-33.

39 Elwes RDC, Marshall J, Beattie A, Newman PK. Epilepsy and employment: a community based survey in an area of high unemployment. F Neurol Neurosurg Psychiatry 1991; 54:200-3

40 Guldvog B. Patient satisfaction and epilepsy surgery. Epilepsia 1994;35:579-84

41 Augustine EA, Novelly RA, Mattson RH, Glaser GH, Williamson PD,Spencer DD, Spencer SS. Occupational adjustement following neurosurgical treatment of epilepsy. Ann Neurol 1984;15:68.

42 Sperling MR, O'Connor MJ, Saykin AJ, Plummer C. Temporal lobectomy for refractory epilepsy. $¥ A M A$ 1996;276: $470-5$.

43 Jacoby A. Impact of epilepsy on employment status: findings from a UK study of people with well controlled epilepsy. Epilepsy Res 1995;21:125-32.

44 BEA. Towards a new understanding. Leeds: British epilepsy association, 1990

45 Morrow J. The clinical, social and psychological consequences of epilepsy. [MD Thesis]. Belfast: Queen's University, 1990.

46 Sperling MR, Saykin AJ, Roberts FD, French JA, O'Connor MJ. Occupational outcome after temporal lobectomy for refractory epilepsy. Neurology 1995;45:970-7. 